\title{
RECIL SD
}

National Cancer Institute

\section{Source}

National Cancer Institute. RECIL SD. NCI Thesaurus. Code C159621.

Less Than 10 percent decrease or less than or equal to 20 percent increase in the sum of longest diameters of target lesions. 